\title{
Optimizing the innovation and development process of medical devices - a study based on angiographic equipment
}

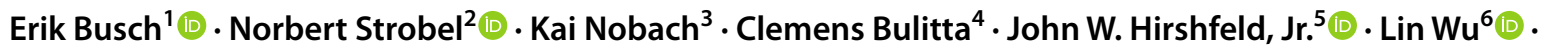 \\ Marcel Gama de Abreu ${ }^{1}$ (D)
}

Received: 18 January 2021 / Accepted: 25 February 2021 / Published online: 13 March 2021

(c) The Author(s) 2021

\begin{abstract}
Cardiovascular diseases are the leading cause of death. The gold standard for their diagnosis and treatment are angiographic procedures, which require specialized equipment. The speed of their continued development is important as better technology enables progress in clinical outcomes. This article proposes a new process model for the innovation and development and shows how to optimize it such that it takes minimal time. The conducted literature research identifies this closed loop process model as being unique in comparison to the well-established models proposed by Brockhoff, Cooper, Crawford, Durfee, Ebert, Eppinger, Hughes, Pleschak, Thom, Ulrich, Vahs and Witt. During a long-term observation of the innovation and development process of angiographic systems 672 data sets on 302 topics were collected over 47 months to validate this process model. The data collected is equivalent to efforts worth 30 man-years. This input was used to calculate key process parameters, analyse key process roles, evaluate the use of problem-solving methods and identify key technologies. We recommend to apply a continuous loop process in the context of innovation and development of medical devices. In the analysed datasets a potential of an up to $20 \%$ shorter process time was identified. Our results can be used for an Activity Based Costing Approach or be applied to bring new or upgraded angiography systems faster to market benefitting patient outcome due to improved diagnosis and treatment. According to the best knowledge of the authors no comparable data collection relating to angiography systems has been performed and presented anywhere else yet.
\end{abstract}

Keywords Medical device $\cdot$ Innovation $\cdot$ Development $\cdot$ Cost of healthcare $\cdot$ Time to market $\cdot$ Problem-solving method

\section{Background}

Erik Busch

erik.busch@web.de

1 Department of Anesthesiology and Intensive Care Medicine, University Hospital Carl Gustav Carus, Dresden, Germany

2 Institute of Medical Engineering Schweinfurt, University of Applied Sciences Würzburg-Schweinfurt, Schweinfurt, Germany

3 Department of Accounting and Management Control, Technical University of Applied Sciences Georg Simon Ohm, Nuremberg, Germany

4 Institute of Medical Engineering, Technical University of Applied Sciences Amberg-Weiden, Weiden, Germany

5 Perelman Center of Advanced Medicine, Cardiac Catherization Laboratory, Hospital of the University of Pennsylvania, Philadelphia, USA

6 Department of Cardiology, Children's Hospital of Fudan University, Cardiovascular Center, Shanghai, China

\subsection{Introduction}

Cardiovascular diseases are the number one cause of death according to the German Federal Statistical Office [1]. While there are regional variances across Europe, heart diseases are associated with about $14 \%$ deaths. Thus, they rank higher in the statistic than cancer and alcohol. [2]

The data for other developed countries outside of Europe is similar. In the USA for example, cardiovascular diseases are responsible for one third of the deaths, totalling up to 800.000 lost lives per year. [3, 4]

Worldwide 17, 9 million people die each year from this cause according to the WHO [5].

The coronary artery disease (CAD) is the deadliest form of cardiovascular diseases. It killed 366.000 US Americans in 2015 [3]. Due to the high importance of CAD this article 
focuses on cardiac heart diseases as a characteristic field for the application of medical devices.

For the diagnosis and treatment of cardiovascular diseases X-ray angiography is still the gold standard. This is a medical imaging technique involving the injection of radioopaque contrast agent into blood vessels such as coronary arteries to highlight them under X-ray. The medical devices that are essential during these angiographic procedures are angiography systems for acquiring X-ray images, recording systems for monitoring vital signs and anaesthesia systems for improving patient care [6]. Therefore, they were selected as especially suitable examples to illustrate the optimization of the innovation and development process for medical devices. Recent examples demonstrating how innovation in the medical device space can improve patient outcome are Fractional Flow Reserve (FFR), Angiographic Computed Tomography (ACT) [7], Machine Learning [8] and image processing based on convolutional neural networks [9].

Due to the importance of these medical devices for the treatment of cardiovascular diseases the time to market of innovations is important. With respect to X-ray guided therapy systems, improved solutions are especially relevant in the area of:

- decision support systems helping clinical experts to deal with complicated interventional cases

- better data integration and presentation to avoid information overflow in an area where ever more powerful systems acquire constantly increasing amounts of data

- seamless flow of information among connected medical systems [10]

- protecting patient and staff from ionizing radiation by effective measures [11, 12]

- usability aspects when developing stronger methods and algorithms that are part of the systems software

- expectations among the user groups that may change around the world. Expectations should be carefully taken into account-for example the iso-centre position of the system should be made adaptable to the height of the operator, or ensuring that disposable medical devices such as catheters are clinically available, e.g., FDA approved, when introducing associated new imaging systems.

- addressing the special needs at each customer site by a special customizable system setup

- straightforward system installation processes avoiding the need of experts that may not be locally available, and

- system concept minimizing total cost of ownership (TCO) to reduce the cost of healthcare and overcome global inequities in access to medical equipment [13].

In addition, the manufacturers of medical devices face the following challenges $[14,15]$ :
- expanding development cycles while market cycles are contracting

- increased price and cost pressure

- managing dynamic load on development teams

- controlling and optimizing of project costs and quality.

Improvements in these areas have a high relevance for the immediate user, the healthcare providers, the patients, the society and last but not least the suppliers. As consequence these areas define the solution space for successful business approaches. An innovation and development process with a strong user focus, especially targeting a user centric design of medical devices utilising the methods of Design Thinking and Usability Engineering, is most likely to explore and fulfil the user needs and other related requirements [16-19].

Technical progress and adjustments in healthcare policies impact this solution space leading to a change in customer expectations and needs, e. g. better anaesthesia approaches, improved imaging technology, or new reimbursement guidelines.

The innovation and development process should be flexible enough to accommodate a change in boundary conditions to enable the development of products and services that meet the market requirements [20].

\subsection{Theoretical framework}

The theoretical basis for a suitable innovation and development process model was established by researching available literature that defined the state-of-the-art. Among the many proposed models for the innovation process [21], we found the following results particular relevant for our work:

- the MedTech Development Process and MedTech Innovation Process by Durfee [22, 23]

- the Phase-Review Process by Hughes [24],

- the Stage-Gate Process in its various evolutions by Cooper [25],

- the Value Proposition Cycle by Hughes [24],

- the process model according to Ulrich and Eppinger [26],

- the model of simultaneous activities by Crawford [27],

- the Three-Phase Model by Thom [28, 29],

- the phase model by Brockhoff [30],

- the phase model by Pleschak [31],

- the innovation process according to Witt [32],

- the innovation process according to Vahs [20] and

- the process of the requirements specification engineering according to Ebert [33].

The publications analysed in the literature research include various individual aspects of the innovation and development process for medical devices that were found to be important for a suitable process model. 
For example, the collaboration between healthcare professionals, medical physicists, clinical engineers, biomedical engineers and the manufacturers of medical devices plays an outstanding role, especially during an agile development process as previously published [34-36].

The most relevant of these input providers for the continued development of medical devices were found to be healthcare professionals, employees of suppliers, competition, market research institutes, trade associations, public corporation and sales [37, 38].

The different challenges found during the utilization of medical devices or services in clinical routine, referred to as topics below. They are identified by these input providers will be analysed and eventually mapped to a development roadmap. This will result in one (or more) task(s) that is (are) assigned according to the responsibilities and processes in a company. The associated task owner could be an individual responsible for carrying out this task alone, or it may be a multidisciplinary team, e.g. input provider. The two task owners which are analysed are the connector and the problem solver due to the importance of their roles. The connectors ensure that the relevant information of the challenge is provided to the problem solver.

The problem solver is tasked to provide the solution to the identified challenge. Solutions can be found through various approaches. These include product modifications, price adjustments, changes in communication and distribution, also referenced as marketing mix. [37]

There is consensus that the Research and Development (R\&D) process is part of the innovation process, which includes the steps: idea generation, selection, preliminary development, development, market introduction and monetisation [39]. During the product development process product properties are defined which determine a product's success. According to the substantial works by Ehrlenspiel [40] and Lindemann [41] the costs of a hardware product are largely determined during construction of the product. Krause specifies up to $75 \%$ [42].

In this context the method of Activity Based Costing $(A B C)$ is useful to reduce cost distortions and thus to allow effective target costing [43-45].

In this context, we also considered known and published quality improvement principles promoting the ideas of process control and continuous improvement, e. g. the work of W. Edwards Deming on the Deming cycle, the Shewhart cycle, the resulting Six Sigma management approach of Plan-Do-Check-Act (PDCA), the FDA Post-Market Device Safety Monitoring, the FDA Sentinel Initiative, the ISO 13485 for medical devices and the VDI guideline 2221.

The medical devices we focus on - such as angiography systems - have an average product life cycle of eight years and an initial investment costs of up to one million Euros [46]. Due to the high up-front investment and long-life span of these systems, upgrades are economically more attractive than the purchase of the new next generation's model [47, 48]. This is a source of motivation for an iterative approach which requires an innovation and development process to be constituted as closed loop.

A simplified representation of the new innovation and development process including the task owners - input providers, connectors and problem solvers - is shown in the following Fig. 1.

The outcomes of a closed-loop process, the role of significant task owners and utilized problem solving methods should be quantitatively measurable such that they can be assessed and optimized using objective, data-driven metrics. This also requires that the role of each participant is clearly defined and that personnel has been properly educated. [49]

Based on analysing previously proposed ideas with respect to how well they can be applied in the context of a medical device manufacturer's innovation process, we arrived at the conclusion that there is currently no scientifically validated and established process model that formulates the innovation and development as closed loop, has a strong user focus and provides quantitative predictions regarding significant task owners and utilized problem solving methods. That gap is closed with this article.

Our working hypothesis is that a lack of a suitable process model, an organizational structure that is not in line, and employees lacking the necessary powers and/or skills and engagement can all cause longer process time.

In this article, we present an innovation and development process designed to shorten the process time to a minimum. We also present data demonstrating the gains that can be made when following the conclusions, we arrived at.

\subsection{Methodology}

Angiography devices and ECG recording systems are essential tools for diagnosis and therapy of cardio-vascular diseases. They have to fulfil stringent legal requirements regarding functionality, reliability, safety, and usability. From a customer's point of view, affordability is also an important criterion.

While state-of-the-art devices meet most requirements to a high degree already, there is still room for improvement, in particular with respect to additional functionality and usability.

The problem solver can utilize the known problem-solving methods (detailed problem definition, dialog method, variation, analogy method, system optimization, combination method, assessment of alternatives and parameter optimization) [50] to find suitable solutions for modifying the product components (software application, mechanics, interfaces between devices, user interface electronics, services). 


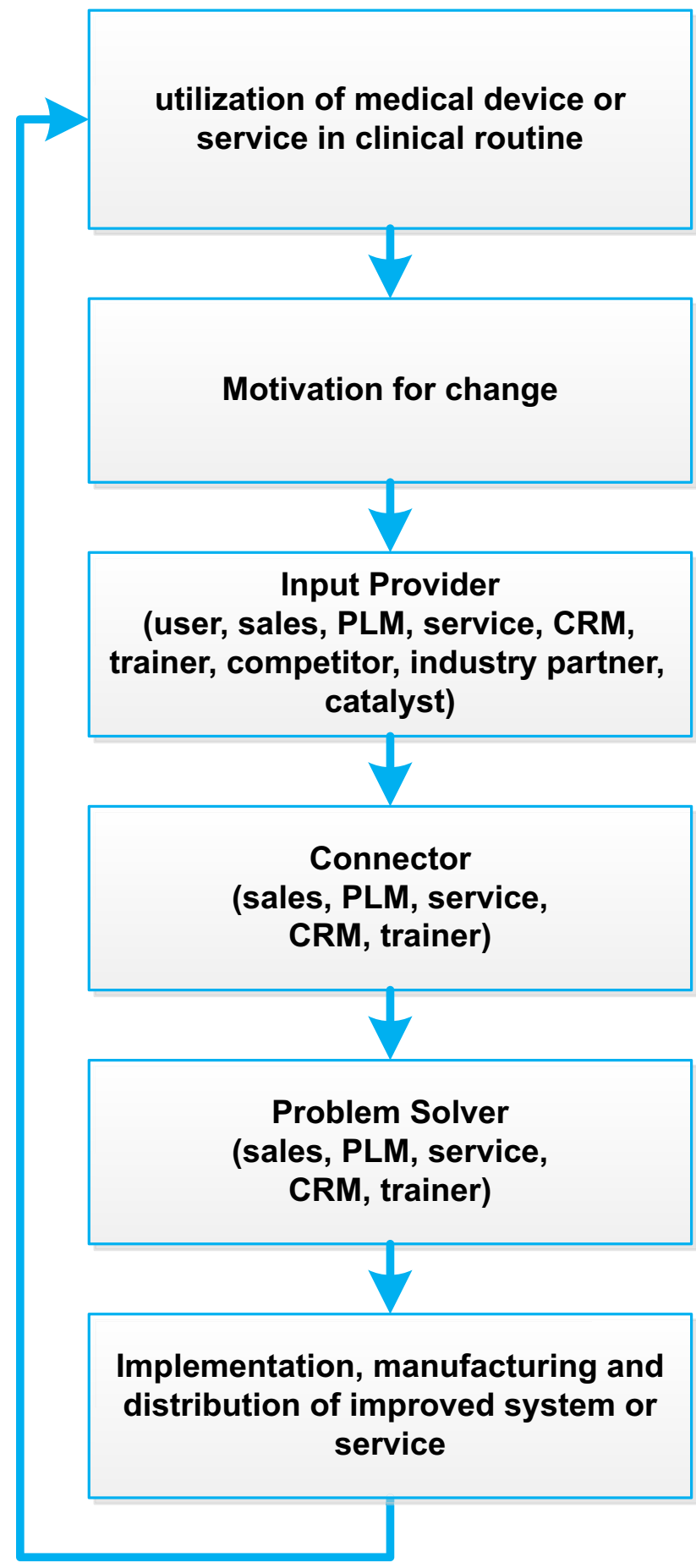

Fig. 1 Simplified representation of the innovation and development process

To propose and validate an optimized innovation and development process, we had to overcome three challenges:

- the collection of sufficient data comprising key process parameters, key roles and key product components of the current processes at a representative manufacturer of angiography systems
- the analysis of this data and the deduction of suitable conclusions and recommendations

- the definition of an appropriate state-of-the-art process model that that meets the above-mentioned requirements with respect to the supply of medical devices for treating deadly diseases such as CAD.

As stated earlier, quantitative metrics for significant task owners and utilized problem solving methods are of value for optimizing it, as they allow concrete measures to be implemented for the organizational structure and the professional employee education. This requires the collection of a sufficient data pool that comprises key process parameters, key roles and key product components of the current processes at a representative manufacturer of medical devices such as angiography systems.

The project management defines its solutions space within the triangle of quality, cost and time. The process time has an impact on the cost and to a certain extend also to the quality. Thus, the process time was defined as the key process parameter with the highest importance. It also determines when new devices offering improved therapy options become available. The goal was the collection of a data pool that facilitated a very reliable measurement of this key process parameter with a statistical power of 0.95 .

As a consequence, a substantial amount of data was required. The total sample size for this quantitative assessment was determined by t-test power analysis [51] to be 284 according to the expectation towards the analysis: $\alpha=5 \%$; $\beta=95 \%$ effect size $=0.21$.

A sample size of 284 means to track 284 topics one or preferably more times from their first appearance in the process until they are considered closed. Based on the calculated sample size the data was gathered over a period of 47 months.

Altogether 672 data points - including detailed information such as task, due date, owner - associated with 302 individual topics - including all aspects of the marketing mix — taken from the innovation and development process of angiography systems were collected. Based on this data the process parameters were analysed and the hypotheses were developed for optimizing the innovation and development process.

The acquired data pool comprises the key process parameters, key roles and key product components of the current processes at a representative manufacturer of angiography systems. Based on this data the following quantitative characteristics could be found for key roles and key product components:

- process time per topic: time between initial input until realization/ implementation,

- number of process steps / task owners per topic, 
- time of owning a task,

- key roles: input provider, connector, problem solver,

product components essential to the solution.

Based on the available data, it was analysed which problem-solving principles were applied and how often. We added our findings to the proposed process model. It is clear that better business processes will improve access to better medical devices, which - in turn - will facilitate better clinical results.

An analysis of related clinical the scope of this paper.

\section{Results}

\subsection{The definition of a new extended innovation and development process model}

From our data, we concluded that the continued development and enhancement of medical devices and related services is primarily stimulated by (see Fig. 1):

- feedback from their use in the clinical routine,

- trends that can be extrapolated from a larger number of iterative enhancements and

- disruptive developments as described by Schumpeter [52] and later by Christensen [53, 54], e.g. breakthrough research results in medicine, natural science and technology, or changes in healthcare policy.

The review of the 50 analysed sources revealed that:

- Two sources show the innovation process as closed loop. All other visualized it as unidirectional, one-time effort, which ends with the production or market introduction.

- One source contains quantitative information for problem solving methods.

Sources of innovation are named in twenty-five papers. In this context, "R\&D" was featured most prominently with twelve references, followed closely by "customers" or "users" that were included eleven times.

We defined that important input providers, who trigger iterative enhancements are users, sales, training/customer education, service, inbound marketing (product lifecycle management, PLM), outbound marketing (customer relationship management, CRM) as well as competitors. The input providers in the model are clustered as follows:

- users (physicians, medical personnel, consumer, customers, clinical community)

- sales,
- employees as named in the literature are further differentiated in:

- product management including innovation (PLM),

- service,

- customer relationship management (CRM)

- training/ customer education,

- research and development (R\&D),

- industry partners (suppliers and industry collaboration partner),

- catalysts,

- competition.

The most important source of information is the direct and indirect communication with the users.

Our data showed that solutions to the topics can be provided by one or any combination of the following aspects of the marketing mix: the (re-)design of products, the adjustment of price, proper customer communication and changes in distribution.

Also, the possibility of overcoming problems with the help of service and training is worth considering.

We also found that the reasons for not fulfilling the users' expectations regarding functionality, usability and cost can mostly contribute to shortcomings of the innovation and development process.

The search for suitable solution principles and their implementation is an important part of the development process. The methods of problem solving are according to Müller [50]: detailed problem definition, abstraction, identification of related challenges, analogy, variation, combination, and dialog method. Analogies, in the sense of using existing solutions or technologies from other industries, are especially relevant. Depending on the individual problem and situation at hand, the methods as well as their application may vary.

Consequent use of known problem-solving methods can lead to a better outcome when developing medical devices and related services.

In an agile development environment following the concepts of the New Product Development Process with short and iterative development cycles, keeping the stakeholders closely in the loop is an important underlying principle [55].

The innovation and development process for angiography and recording systems was found to be a closed loop which is continuously iterated. The process model which emerged from our data is shown in Fig. 2.

\subsection{Quantitative assessment}

We were able to gather altogether 672 data points associated with 302 individual topics. Due to the additional data, 284 


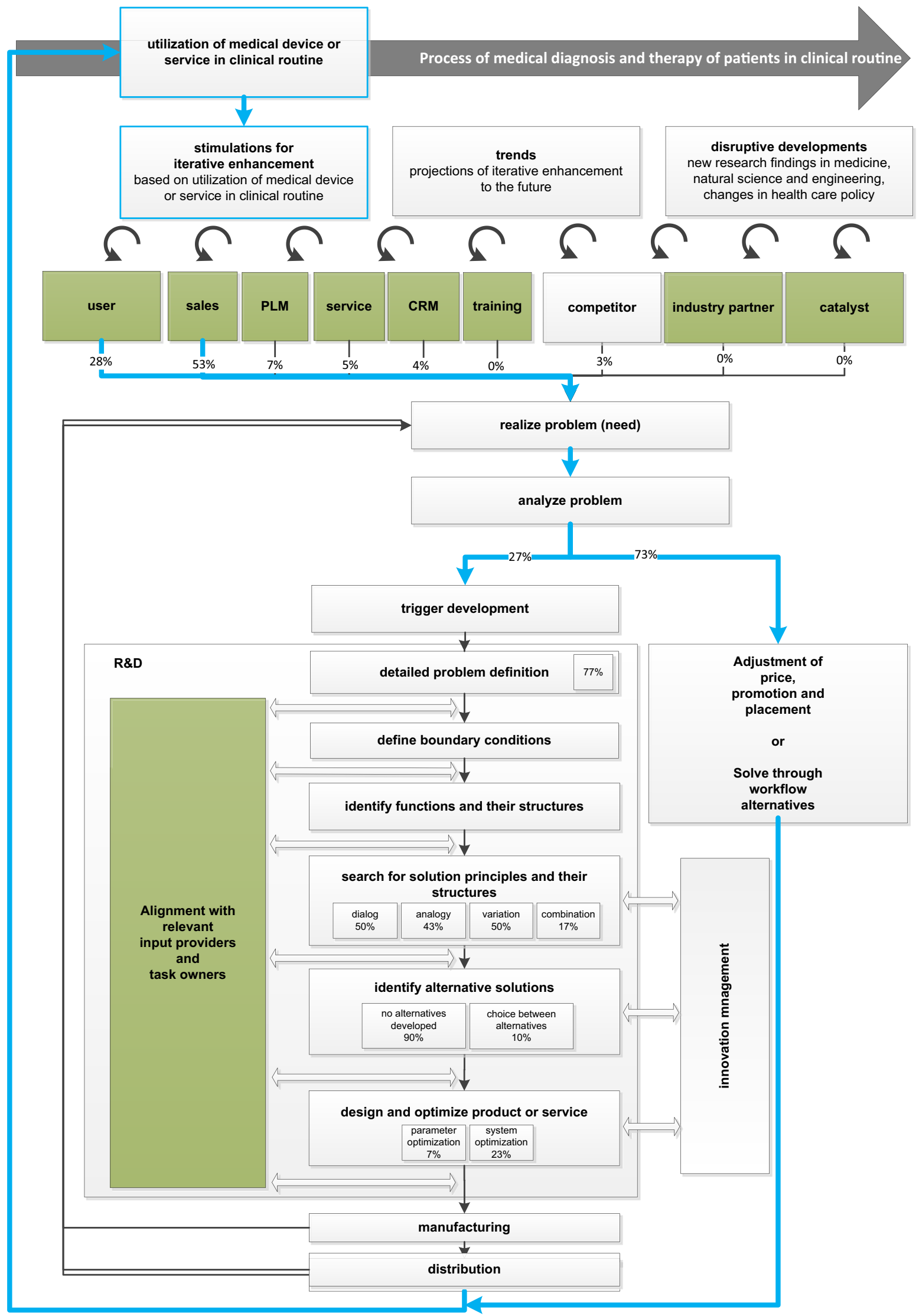

Fig. 2 Extended new process model for optimizing innovation and development of medical devices 
required vs. 302 actuals, the statistical power of the quantitative assessment used in this model is 0.96 and thus exceeds the desired threshold.

Metric data was available for the parameter "process time per topic" and its location as well as form parameter were derived. The median process time $\left(\mathrm{t}_{\mathrm{pd}}\right)$ in this data pool $(n=672)$ is determined to be 10 weeks $(p<0,05)$.

The following hypothesis was formulated based on these results: The process time per topic depends on the number of task owners involved, functions of the task owners, and time per process step.

The verification of the hypothesis "the number of task owners involved $\left(\mathrm{x}_{\mathrm{PA}}\right)$ versus the number of process steps has an impact on the process time per topic" was based on the following metric parameters. The median of number of task owners $\left(\mathrm{x}_{\mathrm{PA}}\right)$ was determined to be 2 . The maximum number of task owners involved in one topic was found to be eleven.

The impact of the number of task owners on the process time was investigated based on this data. The process time increases with the number of task owners as shown in Fig. 3.

Based on the available data the behaviour can be described with the following formula, which has a determination coefficient of $0,96: \mathrm{t}_{\mathrm{pd}}=3,6^{*} \mathrm{x}^{1,4}$.

This confirms the hypothesis that the process time increases with the number of task owners.

The hypothesis that "the time per task owner has an impact on the process time" was confirmed based on the form and location parameters derived from the available data. (Table 1)

The median process time per task owners was found to be: sales 7 weeks, service 11 weeks, CRM 6 weeks, PLM 10 weeks and R\&D 11 weeks.

It is evident that the range of the process time was especially high for some task owners.

The analysis of the nominally scaled data of the parameter "input provider" revealed that the trigger for further

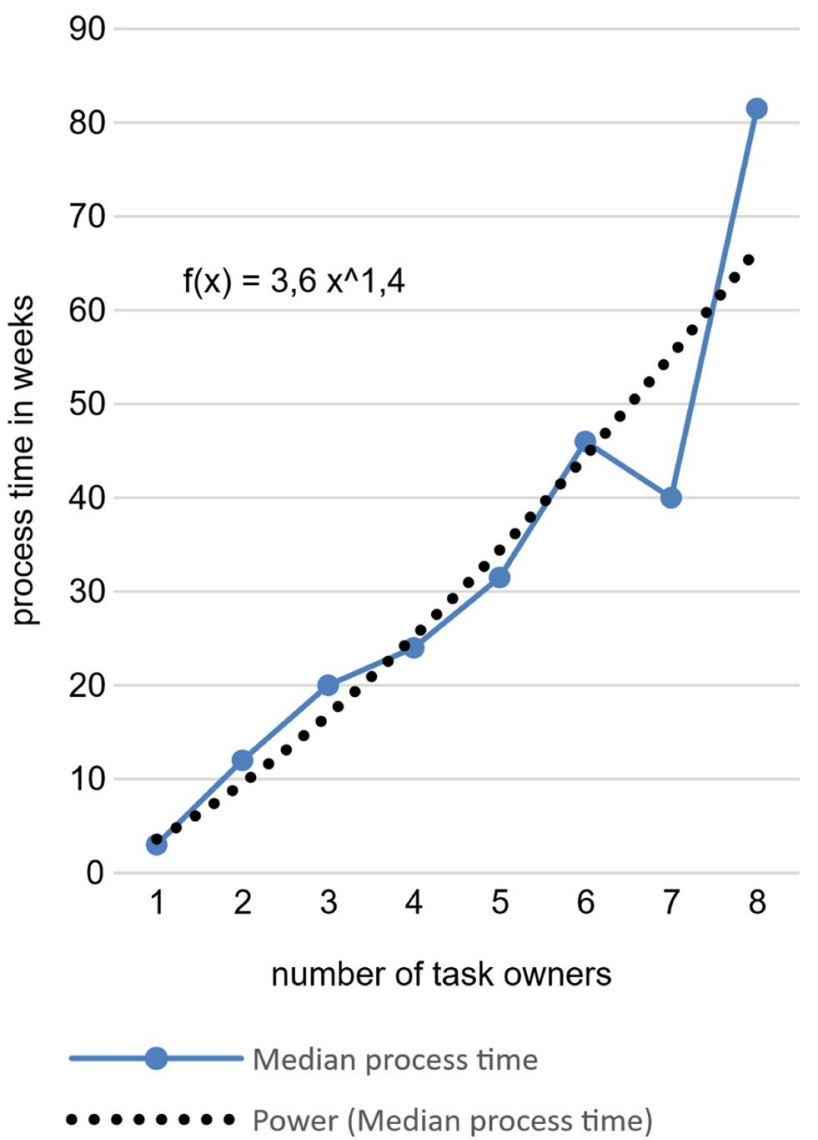

Fig. 3 Median process time in relation to the number of task owners involved

incremental enhancements of the product were provided by sales (53\%), users (28\%), PLM (7\%), service (5\%), CRM (4\%) and other vendors of similar systems (3\%).

We also confirmed the hypothesis "that the function of the involved task owner has an impact on the process time". This finding together with the observation that the process
Fig. 4 Problem solving methods and their utilization rate

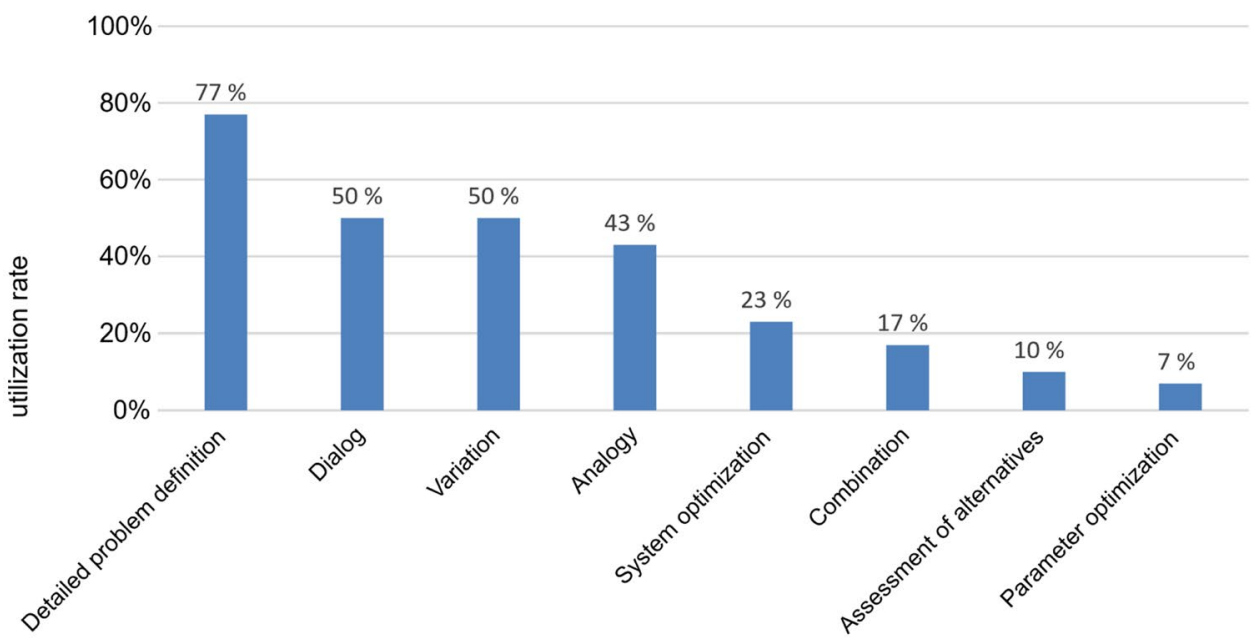


Fig. 5 Changes to product components to solve discovered problems

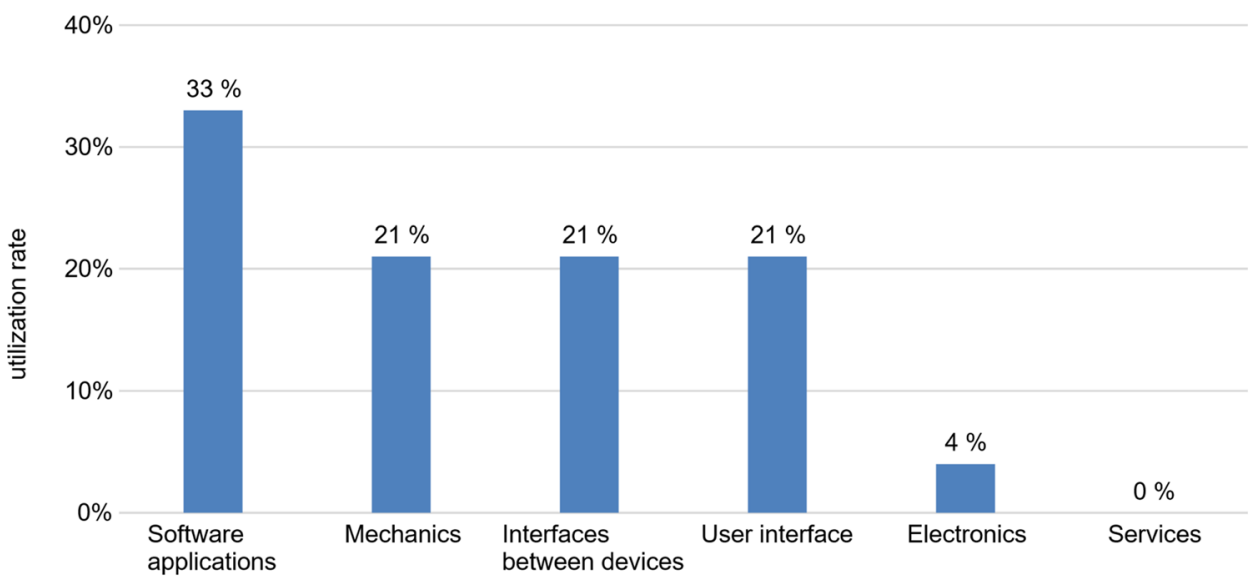

time is related to the number of task owners involved led to the conclusion that the process time could be reduced if the input was directly forwarded to the appropriate problem solver. This is done by the connectors.

The role of these connectors was therefore also looked at. In the acquired data the most prominent connectors were found to be sales (42\%) and PLM (37\%) followed by CRM (14\%).

The problem solvers have several problem-solving methods and their combinations at their disposal [50]. Based on our data, we reviewed how they were applied. How often a particular problem-solving method was used in relation to the overall number of topics is shown in Fig. 4. Since multiple methods can be used for one topic, the sum exceeds $100 \%$.

Discovered problems, when addressed by technical means, are generally solved by changes to existing components of the angiography systems. It was analysed which components were involved and how often. The results are shown in Fig. 5.

The answers to questions related to (new) product development are generated as outcomes of the innovation and development process by the problem solvers. The available nominal data shows that this was PLM (35\%) followed by CRM and R\&D (both 27\%). The involvement of CRM and PLM also proves the hypothesis that the improved solutions can be provided by using the full spectrum of the marketing mix, namely price, promotion and placement in addition to product. In the data pool $27 \%$ of the topics were addressed by technical improvements to the product, while $73 \%$ were solved with other approaches than R\&D.

In addition to the frequency of occurrence also the relation between input provider and problem solver was looked at. This revealed that.

- $20 \%$ of the problems in using the medical product were pointed out by the customer and solved by R\&D. PLM came up in $5 \%$ and $\mathrm{CRM}$ in $2 \%$ of the topics.
- $25 \%$ of the problems in using the systems were flagged by sales and solved by PLM. CRM got involved in these in $21 \%$ of the cases.

Which prompted the question if there were task owners involved that did not primarily contribute to the problem's solution. This can be confirmed for two example groups based on the gathered data of work on 302 topics that lasted 1583 weeks in total.

The first cluster includes topics where the sales was the input provider and CRM the problem solver. The overall process time for all these topics was 995 out of 1583 weeks. Of that PLM owned the tasks for 145 weeks, although they did not contribute to solving the problem. Had PLM passed on these topics without delay, a $15 \%$ process time improvement, equivalent to about 145 weeks, just for this topic cluster could have been achieved. This time is equal to $9 \%$ for the process time for all topics.

A second group of topics clusters comprises sales as input provider and PLM as problem solver. The entire process time for their topics sums up to 381 out of 1583 weeks. During 78 weeks out of this CRM was task owner without being the solution provider. This indicates that there is a potential process time speed-up by $20 \%$, just for this topic cluster. The 78 weeks are equal to $5 \%$ for the process time for all topics.

\section{Discussion}

\subsection{Main results}

The main results of the presented study are:

- The defined innovation and development process model reflects the state-of-art, fulfils the requirements towards the supply of angiography systems and is unique in comparison to the well-established models promoted by 
Brockhoff, Cooper, Crawford, Durfee, Ebert, Eppinger, Hughes, Pleschak, Thom, Ulrich, Vahs and Witt.

- The collection of 672 data points for 302 individual topics taken from the innovation and development process of angiography systems over a period of 47 months allows the assessment of the process time with a statistical power of 0.96 .

- The retrospective analysis of this data reveals key process parameters, key process roles, usage of problem-solving methods and key technologies for providing solutions.

- A relation between the number of task owners and process time could be established.

- The working hypothesis was confirmed by identifying a potential of about $15 \%$ shorter process time in our data and resulting cost savings that can be realised with a suitable model, a proper setup of the organisation and the empowerment of the employees.

\subsection{Implications}

We found an overall optimization potential of about $15 \%$ for all topics included in this long-term observation which is equivalent to four years and thus providing data on the general findings.

This translates into additional costs of 1.8 million EUR, assuming that a team of 5 employees with an average full cost per person of about 90.000 EUR was involved then. In addition, the financial disadvantages for being late to market needs to be considered. They include, for example, loss of revenue and profit, as well as the potential damage to the brand by losing the technology leadership.

The process model that was introduced here is a holistic approach as it lists more relevant input providers and solution strategies, while many other sources in the available literature only consider technical means $(R \& D)$ to generate solutions to the identified topics.

The proposed extended model is considered unique because it acknowledges the fact that the development of medical devices is a continuous loop. Furthermore, the quantitative findings provided with respect to key process parameters, key process owners and utilised problem-solving methods set our model apart from other representations that provide just a qualitative approach.

The role "connector" has a significant impact on the process time and, as a consequence, on the availability of improved solutions to treat cardiac diseases. The selection of the connectors as well as their education and training are crucial for optimizing the innovation and development process. For the latter, advanced methods like e-learning can be employed $[56,57]$. This can be supported by suitable processes and easy-to-use software tools for gathering of findings and forwarding them to the appropriate problem solvers.
The low utilization of "alternatives" as problem-solution method was surprising.

Contrary to an entirely new design of a system the speed of tackling a problem in existing devices is of essence. That could be the reason why the search for alternative solutions was abandoned prematurely. This may also be founded in the development process of medical products itself, which is highly regulated. Thus, the introduction of significant changes would require the modification of many documents which are relevant for the regulatory approval.

Financial functions, e. g. project controllers, can significantly contribute to the overall financial outcome of a development project when they plan sufficient time for developing alternatives.

The practical examples illustrate that paying close attention to mechatronics (electronics and mechanics), information technology (algorithm and software design, user experience and interoperability of systems) is very important when developing new angiography systems. This may also allow conclusions for a market and processoriented cost calculation for individual product components applying the methods of target costing and Activity Based Costing Approach. This also illustrates what skills and expertise are required to develop new systems in the future.

Based on the confirmed hypotheses and on the conducted research in the innovation and development process of a representative supplier for angiography systems the following is recommended for optimizing the innovation and development process of medical devices:

Special attention needs to be paid to the selection of suitable connectors, foremost from sales and PLM, as well as to their education and ongoing training.

It is important to introduce adequate processes and supporting IT tools supporting idea management. Financial considerations shall be an essential part of the planning activities.

A focus should be put on the consequent and extensive usage of proven problem-solving methods.

The market and the working environment of the user need to be known very well to identify problems that can be solved using engineering techniques.

Understanding the flow of information and how it is processed is of particular importance when moving forward with digitalisation and networking of systems installed at healthcare facilities.

At an early stage, technology-inherent challenges and side-effects are to be considered in order to realize the existing innovation potential.

A holistic approach to the system design, including hardware, software, accessories, services, maintenance and implementation has the best chance of success. 
Regional circumstances and peculiarities are to be considered when defining distribution, go-to-market strategy and logistics, as they can pose significant challenges.

The actual working conditions of the user are to be considered early on in the definition and development phase of systems to decide if and which additional software and hardware solutions are required to satisfy the user needs.

The design of the user interface is of utmost importance. User and developer should be involved early and if possible, work together on acceptable solutions.

Consumables and accessories need to be specified early on, e.g., in the system's definition phase such that they are available in sufficient amounts at the time of market introduction.

Systems need to be designed such that they can be customized to achieve optimal outcomes.

The simplification of installation, setup and start-up procedures will reduce human error, minimize training needs and reduce $\mathrm{TCO}$

Realities and capabilities of the distribution channels are to be considered early in the development process. This includes the product, service and upgrade strategies.

The system architecture should facilitate easy maintenance and painless upgrade paths especially for systems with a large installed base and long lifetime. This has an impact on the Total Cost of Ownership (TCO) and competitiveness.

An appropriate multidisciplinary and practical education of the involved task owners is important for the development of innovative and successful products and services, as also promoted by the International Federation for Medical and Biological Engineering (IFMBE) [13].

\subsection{Limitations \& future research}

The following topics hold potential for further research.

The process model introduced here may also be applicable to many other medical devices, e. g. Computer Tomography, anaesthesia systems, other medical application domains, and even other industries.

We also expect that the importance of services will increase as there are unmet user needs, e.g. IT services, financial services, new operating models. This is another topic that is recommended for further research.

Our findings suggest that it is essential for problem solvers to have a quick access to known problems and their solutions. Keeping track of previously observed and resolved issues plays an important role for the manufacturers of medical devices. Therefore, this article and the underlying research anticipate that the innovation management and the consequent use of problem-solving methods will minimize the number of iterations while achieving better outcomes. Its role in ensuring that important data, information and ideas are gathered and provided throughout the innovation and development process is illustrated in the process model.

It is expected that better use of innovation management and the consequent application of appropriate problemsolving methods will minimize the number of iterations required to develop biomedical devices as indicated already for other industries.

The proof of this hypothesis is neither part of this article nor the underlying research, but it is recommended for further considerations.

In addition to the relationship between the number of task owners and process time, the number of all involved individuals and groups might be of relevance. There are advantages and disadvantages to consider before involving particular individual or group. Each addition may potentially add to the development time.

On the other hand, comprehensive input and feedback is needed to ensure that the product, once completed, will meet a user need and therefore be successful in the market place.

Once a group has been established, it is responsible to come up with a design that meets customer needs and is superior to what is offered by the competition. To this end, people from a wide variety of different specialties should be involved in the product start phase selected such that each individual enriches the design process without slowing it down.

Depending on how far along a product has come in the development cycle, people may leave the initial development team, once they are no longer needed to facilitate faster decision making. It is however essential to periodically invite them back to make sure that product development is on track from their perspective as well.

This article focuses on time-to-market. It is, however, understood that many decisions are also made based on financial Key Performance Indicators (KPI) and risks. In order to address this demand, it is considered beneficial to utilize this model to evaluate the various solution strategies and calculate the associated costs.

It was stated that the process model is a closed loop that is run through several times. The number of iterations depends on if and when full customer acceptance is reached. The following hypotheses are derived:

The earlier full customer acceptance is reached, the better the proposed process model was implemented.

A lower quality of implementation and higher cost will correlate directly with a high number of required iterations.

A flawed process implementation may result in products never achieving full customer acceptance. This is likely to result in abandoning the project. The related efforts and sunk cost can be considered waste and should be avoided.

The approach "time to market" that is the fastest possible pass-through of the process is likely to increase the number 
Table 1 Process time per task owner

\begin{tabular}{llllll}
\hline $\begin{array}{l}\text { Time } \\
\text { in weeks }\end{array}$ & sales & Service & CRM & PLM & R\&D \\
\hline min & 1 & 3 & 1 & 0 & 2 \\
1. quartile & 4 & 4 & 3 & 3 & 4 \\
2. quartile & 7 & 11 & 6 & 10 & 11 \\
3. quartile & 16 & 13 & 14 & 20 & 25 \\
max & 133 & 13 & 86 & 108 & 34 \\
data points & 288 & 8 & 95 & 251 & 98 \\
\hline
\end{tabular}

of iterations. As a consequence, it will need more time and investment until the user acceptance is reached.

The approach "time to customer acceptance" is likely to outperform "time to market" in respect of speed, cost and customer satisfaction as already indicated in [58].

The time of 47 months, which was needed to gather the data for this research, was not sufficient to cover enough loops to prove these hypotheses. Therefore, ongoing research on this topic - especially on qualitative assessment, e.g., the iterations needed until full customer satisfaction was reached - is considered worth doing to further improve the innovation and development process of medical devices and potentially other products.

Funding The authors did not receive Support from any organization for the submitted work. No funding was received to assist with the preparation of this manuscript. No funding was received for conducting the study. No funds, grants, or other support was received.

\section{Declarations}

Conflict of interest The authors have no relevant financial or non-financial interests to disclose. The authors have no conflicts of interest to declare that are relevant to the content of this article. All authors certify that they have no affiliations with or involvement in any organization or entity with any financial interest or non-financial interest in the subject matter or materials discussed in this manuscript. The authors have no financial or proprietary interests in any material discussed in this article.

Open Access This article is licensed under a Creative Commons Attribution 4.0 International License, which permits use, sharing, adaptation, distribution and reproduction in any medium or format, as long as you give appropriate credit to the original author(s) and the source, provide a link to the Creative Commons licence, and indicate if changes were made. The images or other third party material in this article are included in the article's Creative Commons licence, unless indicated otherwise in a credit line to the material. If material is not included in the article's Creative Commons licence and your intended use is not permitted by statutory regulation or exceeds the permitted use, you will need to obtain permission directly from the copyright holder. To view a copy of this licence, visit http://creativecommons.org/licenses/by/4.0/.

\section{References}

1. Statistisches Bundesamt. Todesursachen Deutschland. 2016. In: Todesursachen Deutschland. Statistisches Bundesamt. https:// www.destatis.de/DE/ZahlenFakten/GesellschaftStaat/Gesundheit/ Todesursachen/Todesursachen.html\#Tabellen. Accessed 16 Jan 2021.

2. Cayotte E, Buchow H. Population and social conditions. In: Statistics in Focus. Eurostat. 2009. https://ec.europa.eu/eurostat/ documents/3433488/5283933/KS-SF-09-067-EN.PDF/c509a32a080e-4e98-9d48-d874c1b016e4?version=1.0. Accessed 16 Jan 2021.

3. National Heart, Lung, and Blood Institute. Know the Difference: Cardiovascular Disease, Heart Disease, Coronary Heart Disease. In: Know the Difference Fact Sheet. NHLBI Publications and Resources. 2015. https://www.nhlbi.nih.gov/sites/default/files/publications/ FactSheetKnowDiffDesign2020V4a.pdf2020V4a.pdf. Accessed 16 Jan 2021.

4. National Heart, Lung, and Blood Institute, Morbidity \& Mortality: 2012 Chart Book on Cardiovascular, Lung and Blood Diseases. In: NHLBI Research Docs. 2012; https://www.nhlbi.nih.gov/files/ docs/research/2012_ChartBook_508.pdf. Accessed 16 Jan 2021.

5. World Health Organization (WHO). Cardiovascular Diseases - Overview. In: Health topics. 2021. https://www.who.int/health-topics/cardiovasculardiseases/\#tab=tab_1. Accessed 16 Jan 2021.

6. Hemmes SN, Gama de Abreu M, Pelosi P, Schultz MJ. PROVE Network Investigators for the Clinical Trial Network of the European Society of Anaesthesiology, High versus low positive end-expiratory pressure during general anaesthesia for open abdominal surgery (PROVHILO trial): a multicentre randomised controlled trial. Lancet. 2014; https:// doi.org/10.1016/s0140-6736(14)60416-5.

7. Strobel N, et al. 3D Imaging with Flat-Detector C-Arm Systems. In: Reiser M., Becker C., Nikolaou K., Glazer G. (eds) Multislice CT. Medical Radiology. Berlin, Heidelberg: Springer; 2009. https:// doi.org/10.1007/978-3-540-33125-4_3.

8. Ed-daoudy A, Maalmi K. Real-time heart disease detection and monitoring system based on fast machine learning using Spark. Health Technol. 2020. https://doi.org/10.1007/s12553-020-00460-3.

9. Rostami A, Amirani MC, Yousef-Banaem H. Segmentation of the left ventricle in cardiac MRI based on convolutional neural network and level set function. Health Technol. 2020. https://doi. org/10.1007/s12553-020-00461-2.

10. Hammami R, Bellaaj H, Hadj KA. Interoperability for medical information systems: an overview. Health Technol. 2014. https:// doi.org/10.1007/s12553-014-0085-8.

11. Fiorilli PN, Kobayashi T, Giri J, Hirshfeld JW. Strategies for radiation exposure-sparing in fluoroscopically guided invasive cardiovascular procedures. Catheter Cardiovasc Interv. 2020. https://doi.org/10.1002/ ccd.28281.

12. Bai J, Wang F, Yang H, Lu Y, Wu L. Reducing radiation dose in paediatric interventional cardiac catheterisation. Cardiol Young. 2019. https://doi.org/10.1017/s1047951119001252.

13. Goh J. Systems medicine for the delivery of better healthcare services - International Federation for Medical and Biological Engineering (IFMBE) perspective. Health Technol. 2017. https://doi.org/10.1007/ s12553-016-0165-z.

14. Tiam Kapen P, Kouam Kouam S, Tchatchouang TC, et al. Theoretical and experimental investigation of a portable electrocardiograph adapted for low-income countries. Health Technol. 2020. https://doi. org/10.1007/s12553-020-00432-7.

15. Clark D, Dean G, Bolton S, et al. Bench to bedside: The technology adoption pathway in healthcare. Health Technol. 2020. https://doi. org/10.1007/s12553-019-00370-z. 
16. Hofbauer G, Sangl A. Professionelles Produktmanagement: Der prozessorientierte Ansatz, Rahmenbedingungen und Strategien. 3rd ed. Erlangen: Publicis; 2017.

17. Seibert $\mathrm{S}$. Technisches Management: Innovationsmanagement Projektmanagement - Qualitätsmanagement. 1st ed. Wiesbaden: Teubner Verlag; 1998.

18. Giuliani M, Szczęśniak-Stańczyk D, Mirnig N, et al. User-centred design and evaluation of a tele-operated echocardiography robot. Health Technol. 2020. https://doi.org/10.1007/s12553-019-00399-0.

19. Soliman E, Mogefors D, Bergmann JHM. Problem-driven innovation models for emerging technologies. Health Technol. 2020. https://doi. org/10.1007/s12553-020-00450-5.

20. Vahs D, Burmester R. Innovationsmanagement: Von der Produktidee zur erfolgreichen Vermarktung. 3rd ed. Stuttgart: Schäffer-Poeschel; 2005.

21. Meissner D, Kotsemir M. Conceptualizing the innovation process towards the 'active innovation paradigm' - trends and outlook. J Innov Entrep. 2016. https://doi.org/10.1186/s13731-016-0042-z.

22. Durfee W, Iaizzo P. The Medical Device Innovation Process. In: Engineering in Medicine. London: Academic Press; 2019;495509. https://doi.org/10.1016/B978-0-12-813068-1.00019-1.

23. Durfee W, Iaizzo P. Medical Device Innovation Handbook. 7th ed. Minneapolis: LuLu Press; 2018.

24. Hughes GD, Chafin DC. Turning New Product Development into a Continuous learning process. J Prod Innov Manag. 1996. https:// doi.org/10.1016/0737-6782(95)00112-3.

25. Cooper R, DeGroote M. Overhauling the new product process. Ind Mark Manage. 1996. https://doi.org/10.1016/S0019-8501(96)00062-4.

26. Ulrich K, Eppinger S, Yang MC. Product Design and Development. 7th ed. Columbus: McGraw Hill; 2020.

27. Crawford C, Di Benedetto CA. New Products Management. 12th ed. Columbus: McGraw-Hill; 2021.

28. Thom N. Innovation management in small and medium-sized firms. Management International Review - Journal of International Business. 1990;30:181-2.

29. Thom N. Innovationsmanagement. 1st ed. Bern: Schweizerische Volksbank; 1992.

30. Brockhoff K. Forschung und Entwicklung - Planung und Kontrolle. 5th ed. Berlin: De Gruyter; 1999. https://doi. org/10.1515/9783486700855.

31. Pleschak F, Sabisch H. Innovationsmanagement. 1st ed. Stuttgart: Schäffer-Poeschl; 1996.

32. Witt J. Produktinnovation: Entwicklung und Vermarktung neuer Produkte. 1st ed. München: Vahlen; 1996.

33. Ebert G, Pleschak F, Sabisch H. Aktuelle Aufgaben des Forschungsund Entwicklungs-Controlling in Industrieunternehmen. In: Bericht - Fraunhofer-Institut für Systemtechnik und Innovationsforschung. Wiesbaden: Gabler; 1992. pp. 137-157

34. Koutsouris D. The evolution of medical care: from the beginnings to personalized medicine. Health Technol. 2017. https://doi.org/10.1007/ s12553-016-0163-1.

35. Tabakov S. Systems Medicine - perspectives for collaboration between medical physicists and biomedical engineers. Health Technol. 2017. https://doi.org/10.1007/s12553-016-0166-y.

36. David Y, Judd T. Evidence-based impact by clinical engineers on global patients outcomes. Health Technol. 2020. https://doi. org/10.1007/s12553-019-00345-0.

37. Nieschlag M, Dichtl E, Hörschgen H. Marketing. 19th ed. Berlin: Duncker \& Humblot. 2002

38. Koppelmann U. Produktmarketing: Entscheidungsgrundlagen für Produktmanager. 6th ed. Berlin, Heidelberg: Springer; 2013.
39. Matzke H. F\&E-Controlling. In: Controlling Wiki. 2020. https:// www.controlling-wiki.com/de/index.php/F\&E-Controlling. Accessed 16 Jan 2021.

40. Ehrlenspiel K, Lindemann U, Kiewert A. Cost-Efficient Design 1st ed. Berlin: Springer; 2007.

41. Lindemann U. Handbuch Produktentwicklung. 1st ed. München: Carl Hanser Verlag; 2016.

42. Krause W. Grundlagen der Konstruktion - Lehrbuch für Elektroingenieure. 6th ed. Berlin: VEB Verlag Technik; 1989. p. 14.

43. Cooper R. The Rise of Activity-Based Costing-Part Three: How Many Cost Drivers Do You Need and How Do You Select Them? Journal of Cost Management. 1989;2(4):34-46.

44. Drury C. Activity-based costing. In: Management and Cost Accounting. 3rd edition. Boston, MA: Springer; 1992. https:// doi.org/10.1007/978-1-4899-6828-9_11.

45. Swain MR, Fawcett SE. Activity-Based Costing. In: Swamidass PM, editors. Innovations in Competitive Manufacturing. Boston, MA: Springer; 2000. https://doi.org/10.1007/978-1-4615-1705-4_31.

46. Lee J. Average cost of angiography system up $26 \%$ in June. In: Modern Healthcare. 2014. https://www.modernhealthcare.com/ article/20141008/NEWS/310089965/average-cost-of-angiographysystem-up-26-in-june. Accessed 16 Jan 2021.

47. Sferrella S. Equipment Service: Total Cost of Ownership. In: Radiology Business. 2012. https://www.radiologybusiness.com/ topics/technology-management/equipment-service-total-costownership. Accessed 16 Jan 2021.

48. Ryckx N, Sans-Merce M, Meuli R, Zerlauth J, Verdun F. System upgrade on Philips Allura FD20 angiography systems: Effects on patient skin dose and static image quality. Radiat Prot Dosimetry. 2016. https://doi.org/10.1093/rpd/ncv484.

49. Schultz JS, Sjøvold E, André B. Can formal innovation training improve group- and organizational-level innovativeness in a healthcare setting?

50. Müller J. Arbeitsmethoden der Technikwissenschaften: Systematik, Heuristik, Kreativität. 1st ed. Berlin: Springer; 1990. https:// doi.org/10.1007/978-3-642-93442-1.

51. Einbock S. Statistik für Ingenieure und Naturwissenschaftler. 3rd ed. Nordersted: Books on Demand; 2018.

52. Schumpeter J. Capitalism, Socialism, and Democracy. 3rd ed. New York: Harper Perennial Modern Classics; 2008.

53. Christensen CM. Innovator's Dilemma: When New Technologies Cause Great Firms to Fail. reprint. Boston: Harvard Business Review Press; 2013.

54. Christensen CM, Raynor ME. Innovator's Solution: Creating and Sustaining Successful Growth. revised. Boston: Harvard Business Review Press; 2013.

55. Galway L, O'Neill S, Donnelly M, et al. Stakeholder involvement guidelines to improve the design process of assistive technology: lesson from the development of the MPVS system. Health Technol. 2013. https://doi.org/10.1007/s12553-013-0048-5.

56. Kožuško J, Ku $\beta$ J, Abdel-Haq A, Weichelt C, Dietrich H, Hebestadt $\mathrm{S}$, Rudolph I, Morgenstern U. Evaluation of an e-learning scenario for biomedical engineers. In: Procedia - Social and Behavioural Sciences. 2012; https://doi.org/10.1016/j.sbspro.2012.09.553.

57. Tabakova V. E-learning - from first experiences in medical physics and engineering to its role in times of crisis. Health Technol. 2020. https://doi.org/10.1007/s12553-020-00474-x.

58. González-Cristiano A, Sandberg B. When running fast is not the best option: failure of user involvement in design development processes. Int J Prod Dev. 2019. https://doi.org/10.1504/ IJPD.2019.105485. 